\title{
BOUNDS ON THE CURVATURE FOR FUNCTIONS WITH \\ BOUNDED BOUNDARY ROTATION OF ORDER 1-b
}

\author{
M. A. NASR \\ Department of Mathematics \\ Faculty of Science \\ Mansoura University, Egypt \\ (Received April 30, 1985 and in revised form July 2, 1985)
}

ABSTRACT. Let $v_{k}(1-b), k \geq 2$ and $b \neq 0$ real, denotes the class of locally univalent analytic functions $f(z)=z+\sum_{n=2}^{\infty} a_{n} z^{n}$ in $D=\{z:|z|<1\}$ such that $\int_{0}^{2 \pi}\left|\operatorname{Re}\left\{1+\frac{1}{b} \frac{z f^{\prime \prime}(z)}{f^{\prime}(z)}\right\}\right| d \theta<\pi k, z=r^{i \theta} \in D$. In this note sharp bounds on the curvature of the image of $|z|=r, 0<r<1$, under a mapping $f$ belonging to the class $v_{k}(l-b)$ have been obtained.

KEY WORDS AND PHRASES. Analytic Function, Univalent Functions, Functions with Bounded Boundary Rotation.

1980 AMS SUBJECT CLASSIFICATION CODES. $30 C 45$.

1. INTRODUCTION.

Let $A$ denote the class of functions $f(z)=z+\sum_{n=2}^{\infty} a_{n} z^{n}$ which are analytic in $D=\{z:|z|<1\}$. For $G \in A$, we say $G$ belongs to the class $s(1-b)(b \neq 0$ complex) if and only if $G(z) / z \neq 0$ in $D$ and $\operatorname{Re}\left\{1+\frac{1}{b}\left(\frac{z G^{\prime}(z)}{G(z)}-1\right)\right\}>0, z \in D$.

The class S(1-b) was introduced by Nasr and Aouf in [1]. It is shown in [1] that $G \in S(1-b)$ if and only if there is a function $g \in S(0)$ such that

$$
G(z)=z[g(z) / z]^{b} \text {. }
$$

and for $b \neq 0$ real

$$
\begin{aligned}
& (1+r)^{-2 b} \quad \leq|G(z) / z| \leq \begin{array}{l}
(1-r)^{-2 b} \\
(1+r)^{-2 b} \\
(1-r)^{-2 b}
\end{array} \\
& \text { Let } v_{k}(1-b), \quad K \geq 2 \text { and } b \neq 0 \text { complex, denotes the class of functions } f \in A
\end{aligned}
$$

which satisfy $f(z) \neq 0$ in $D$ and

$$
\begin{aligned}
& \int_{0}^{2 \pi}\left|\operatorname{Re}\left\{1+\frac{1}{b} \frac{z f^{\prime \prime}(z)}{f^{\prime}(z)}\right\}\right| d \theta \leq \pi k, \quad z=r e^{i \theta} \in D . \\
& \text { The class } v_{k}(1-b) \text { was introduced by Nasr [ }\left[\text { ]. It was shown in [2] that } f \circ v_{k}(1-b)\right.
\end{aligned}
$$
if and only if there exist two functions $g_{1}, g_{2} \in S(0)$ such that 


$$
f^{\prime}(z)=\left\{g_{1}(z) / z\right\}^{b(k+2) / 4} /\left\{g_{2}(z) / z\right\}^{b(k-2) / 4}
$$

And from (1.1) and (1.4) we deduce immediately that $f \in v_{k}(1-b)$ if and only if there exist two functions $G_{1}, G_{2} \in S(1-b)$ such that

$$
f^{\prime}(z)=\left\{G_{1}(z) / z\right\}^{(k+2) / 4} /\left\{G_{2}(z) / z\right\}^{(k-2) / 4}
$$

The subclasses $\mathrm{S}(1-\mathrm{b}), \mathrm{V}_{2}(1-b)$ and $\mathrm{V}_{\mathrm{k}}(1-b)$ are respectively, classes of functions starlike of order 1-b, convex of order $1-b$ and of bounded boundary rotation of order $1-b$. We shall denote the subclasses $v_{2}(1-b)$ and $\left.v_{h}{ }^{\prime}\right)$ respectively by $\mathrm{C}(1-\mathrm{b})$ and $\mathrm{v}_{\mathrm{k}}$.

For a locally univalent function $f$ in $D$ the curvature $K_{r}^{f}(z)$ at the point $\mathrm{w}=\mathrm{f}(\mathrm{z})$ for the level line, i.e. the image of the circle $|z|=r$ under the mapping $f$, is given by

$$
K_{r}^{f}(z)=\operatorname{Re}\left\{1+\frac{z f^{\prime} '(z)}{f^{\prime}(z)}\right\} /\left|z f^{\prime}(z)\right|
$$

Let inf $K_{r}^{B}$ and sup $K_{r}^{B}$ denote respectively, the infimum and supremum of $K_{r}^{f}(z)$ for $|z|=r$ when $f$ beiongs to a certain subclass $B$ of locally univalent functions in $A$, which is normal and compact.

The problem of estimating $\mathrm{K}_{\mathrm{r}}^{\mathrm{f}}(\mathrm{z})$ for various classes of functions has attracted considerable attention (see [3, p.p. 599-601] for the history of this problem).

The purpose of this paper is to establish inf $\mathrm{K}_{\mathrm{r}} \mathrm{V}_{\mathrm{k}}$ and $\operatorname{sup~}_{\mathrm{r}} \mathrm{V}_{\mathrm{k}}(1-\mathrm{b})$ for $\mathrm{b} \neq$ o real.

2. STATEMENT OF RESULTS.

Set $k_{1}=(k-2) / 4$ and $H(r)=\left(1+r^{2}\right) / 2 r \quad-\{\log (1+r) /(1-r)\}^{-1}, 0<r<1$.

A simple calculation shows that $H(r)$ increases strictly with $r$ and that $0<H(r)<1$.

THEOREM 1. If $\mathrm{f} \in \mathrm{V}_{\mathrm{k}}(\mathrm{l}-\mathrm{b}), \mathrm{b}>0$, then

$$
\inf k_{r}^{V_{k}(1-b)}=\left\{\begin{array}{l}
\left(1-r^{2}\right)^{b} / r \quad \text { for } k=2,0<b<1, \\
\frac{(1+r)^{2 b\left(k_{1}+1\right)-1}}{r(1-r)^{2 b k_{1}+1}\{1-b k r+(2 b-1) r\} \text { otherwise }}
\end{array}\right.
$$

and

$$
\sup K_{r} V_{k}(1-k)=\left\{\begin{array}{c}
\frac{(1-r)^{r(1-b)+b}}{r(1+r)^{r(1-b)-b}\left\{\frac{e}{2 r} \frac{(1-r)(1+r)^{2} / 2 r}{(1+r)}(1-r)^{2} / 2 r\right.} \log \left(\frac{1+r}{1-r}\right)^{1+b k_{1}} \\
\text { for } r-\frac{b\left(k_{1}+1\right)}{1+b k_{1}}(1+r)<H(r)<r+\frac{b\left(k_{1}+1\right)}{1+b k_{1}}(1-r) \\
\frac{(1-r)^{2 b\left(k_{1}+1\right)-1}}{r(1+r)^{2 b k_{1}+1}} 1+b k r+(2 b-1) r^{2} \text { otherwise }
\end{array}\right.
$$

These bounds are sharp for all $0<\mathrm{r}<1$. 
THEOREM 2. If $t \in v_{k}(1-b), b<0$, then

$$
\inf k_{r} V_{k}(1-b)=\frac{(1-r)^{2 b\left(k_{1}+1\right)-1}}{r(1+r)^{2 b k_{1}+1}}\left(1+b k r+(2 b-1) r^{2}\right\}
$$

and

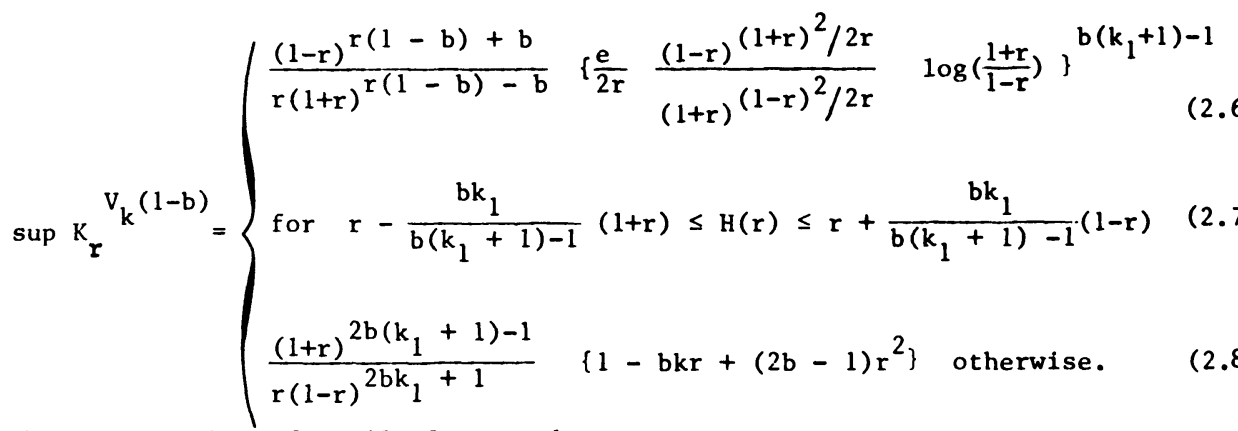

These bounds are sharp for all $0<\mathrm{r}<1$.

Indeed, if $k=2, b>0$ our results coincide with the results given for inf $K_{r}^{c(1-b)}$ and $\sup K_{r}^{c(1-b)}$ by Singh [7], also for $k=2,0<b \leq 1$, our results are reduced to those giver for inf $K_{r}^{c(1-b)}$ and $\sup K_{r}^{c(1-b)}$ by Zederkiewicz [4] and those given by Eenigenburg [5] for inf $\mathrm{K}_{\mathrm{r}}^{\mathrm{c}(1-\mathrm{b})}$. Moreover, for $k=2, b=1$, coincide with those given for inf $K_{r}^{c(0)}$ and $\sup _{r}^{c(0)}$ by Zmorovic [6] and those given by Keogh [7] for inf $K_{r}^{c(0)}$. Finally, if $b=1$ our results agree with those reached by Noonan [8] and Singh [9] for inf $K_{r}{ }^{V_{k}}$ and $\sup K_{r} V_{k}$. But to the best of our knowledge the values of inf $k_{r}^{c(1-b)}$ and $\sup k_{r}^{c(1-b)}$ for $b<0$ and also the values of inf $k_{r} v_{k}(1-b)$ and $\sup k_{r} v_{k}(1-b)$ for $b<0$ and also the values of inf $k_{r}$ and sup $k_{r}^{V_{k}(1-b)}$ for $b \neq 1$ are not known as yet.

3. PROOFS.

We need the following:

LEMMA $1[9]$ : If $g \in \mathrm{S}(0), z=r \mathrm{e}^{i \theta} \in \mathrm{D}$, then

$$
\left(1-r^{2}\right)\left|\frac{g(z)}{z}\right| \leq \operatorname{Re} \frac{z g^{\prime}(z)}{g(z)} \leq \frac{1+r}{1-r}+\frac{2 r \log \left|\left(1-r^{2}\right) g(z) / z\right|}{\left(1-r^{2}\right) \log \{(1+r) /(1-r)\}}
$$

Both sides of the above inequality are sharp.

COROLLARY 1. If $G \in \mathrm{S}(1-\mathrm{b}), z=\mathrm{re}^{\mathrm{i} \theta} \in \mathrm{D}$, then

$$
\begin{array}{lrl}
B(r, G(z) / z) & A(r, G(z) / z) & \text { for } b>0 \\
A(r, G(z) / z) & \leq \operatorname{Re} \frac{z G^{\prime}(z)}{G(z)} \leq & \\
B(r, G(z) / z) & \text { for } b<0
\end{array}
$$


where

and

$$
A(r, x)=\frac{1+(2 b-1) r}{1-r}+\frac{2 r \log \left|(1-r)^{2 b} x\right|}{\left(1-r^{2}\right) \log [(1+r) /(1-r)]}
$$

$B(r, x)=(1-b)+b\left(1-r^{2}\right)|x|^{1 / b}$

PROOF. The proof will follows immediately from (1.1) and (3.1)

PROOF OF THEOREM i. Set

$\left|G_{1}(z) / z\right|=u$ and $\left|G_{2}(z) / z\right|=v$.

Then from (2.2), we find that $u$ and $v$ lie in the interval

$\left[1 /(1+r)^{2 b}, 1 /(1-r)^{2 b}\right]$.

In view of (1.5) and (1.6) we need to find the extreme values of

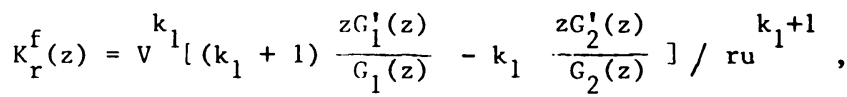

In view of (3.2) and (3.6) we need to obtain the minimum of

$\mathrm{F}(\mathrm{u}, \mathrm{v})=\mathrm{v}^{\mathrm{k}_{1}}\left[\left(\mathrm{k}_{1}+1\right) B(\mathrm{r}, \mathrm{u})-\mathrm{k}_{1} \mathrm{~A}(\mathrm{r}, \mathrm{v})\right] / \mathrm{ru}^{\mathrm{k}_{1}+1}$

and the maximum of

$$
H(u, v)=v^{k_{1}}\left[\left(k_{1}+1\right) A(r, u)-k_{1} B(r, v)\right] / r u^{k_{1}+1}
$$

when $u$ and $v$ lie in the interval given by (3.5).

This reduces the problem to finding extreme values of functions of two variables. It is easily seen that for $0<b \leq 1$ and $k=2\left(k_{1}=0\right)$ the minimum is attained for

$$
u=1 /\left(1-r^{2}\right)^{b}
$$

and because the value of $u$ lies within the interval given by (3.5) this gives the minimum. We thus obtain (2.1). If $k=2, b>1$ or $k>2, b>0$ it is readily confirmed that the roots of

$$
\frac{\partial F}{\partial u}=0=\frac{\partial F}{\partial v}
$$

do not give the minimum. Hence, the minimum is attained on the boundary for $u=1 /(1-r)^{2 b}$ and $v=1 /(1-r)^{2 b}$. This yields (2.2).

In order to maximize $\mathrm{H}(\mathrm{u}, \mathrm{v})$, it is found that the equations

give $\frac{\partial H}{\partial u}=0=\frac{\partial H}{\partial v}$

$$
v=\left\{2 r /\left(1-r^{2}\right)^{2} \log [(1+r) /(1-r)]\right\}^{b}
$$

and

$$
\log \left[(1-r)^{2 b} \quad U\right]=\frac{1+b k_{1}}{1+k_{1}}-\left[\frac{1+b k_{1}}{1+k_{1}}+\frac{2 b r}{1-r}\right] \frac{\left(1-r^{2}\right)}{2 r} \log \left(\frac{1-r}{1-r}\right)
$$

The value of $v$ given by (3.10) lies in the interval given by (3.5) because

$$
2 r /(1+r)^{2} \leq \log [(1+r) /(1-r)] \leq 2 r /(1-r)^{2}
$$


but the value of $u$ given by (3.11) lies in the interval given by (3.5) if

$$
r-\left[b\left(1+k_{1}\right)(1+r) /\left(1+b k_{1}\right)\right] \leq H(r) \leq r+\left[b\left(1+k_{1}\right)(1-r) /\left(1+b k_{1}\right)\right] \text {. }
$$

This gives (2.3). When (3.13) does not hold, the maximum values of (3.8) is obtained on the boundary for $u=1 /(1-r)^{2 b}$ and $v=1 /(1+r)^{2 b}$. This yields (2.4).

The above inequalities are sharp and the extremal functions are given below where equality in each case, is attained at $z=r$.

(i) For equality in (2.1)

$$
\mathrm{f}_{1}^{\prime}(\mathrm{z})=1 /\left[\left(1-z \mathrm{e}^{\mathrm{it}}\right)^{\lambda}\left(1-z \mathrm{e}^{-i \mathrm{t}}\right)^{(1-\lambda)}\right]^{\mathrm{b}}, 0 \leq \lambda \leq 1,0<\mathrm{b} \leq 1 \text {, where }
$$

$\cos t=r$ and $\lambda b=\frac{1+r^{2}}{r}+(1-b) r-H(r)$

(ii) For equality in (2.2)

$$
f_{2}^{\prime}(z)=(1-z)^{2 b k_{1}} /(1+z)^{2 b\left(1+k_{1}\right)}
$$

(iii) For equality in (2.3)

$$
f_{3}^{\prime}(z)=\left(1-z e^{-i t}\right)^{2 b k_{1}} 1 \frac{(1-z)\left(1+b k_{1}\right) H(r)+r(b-1)-b\left(1+k_{1}\right)}{(1+z)\left(1+b k_{1}\right) H(r)+(b-1)+b\left(1+k_{1}\right)}
$$

where

$$
1+r^{2}-2 r \cos t=\left(1-r^{2}\right)^{2} /\left[1+r^{2}-2 r H(r)\right]
$$

(iv) For equality in (2.4)

$$
\mathrm{f}_{4}^{\prime}(\mathrm{z})=(1+\mathrm{z})^{2 \mathrm{bk}} 1 /(1-\mathrm{z})^{2 \mathrm{~b}\left(\mathrm{k}_{1}+2\right)}
$$

PROOF OF THEOREM 2. Taking into consideration $(1.3),(1.5),(1.6),(3.3)$ and using the notation $G_{1}(z) / z=u$ and $G_{2}(z) / z=v$, we find that for $u$ and $v$ lie in the interval

$$
\left[1 /(1-r)^{2 b}, 1 /(1+r)^{2 b}\right] \text {, }
$$

we need to obtain the minimum of

$$
F_{1}(u, v)=v^{k}\left[\left(1+k_{1}\right) A(r, u)-k_{1} B(r, v)\right] / r u^{1+k_{1}}
$$

and the maximum of

$$
\left.\mathrm{H}_{1}(\mathrm{u}, \mathrm{v})=\mathrm{v}^{\mathrm{k}_{1}}\left(1+\mathrm{k}_{1}\right) \mathrm{B}(\mathrm{r}, \mathrm{u})-\mathrm{k}_{1} \mathrm{~A}(\mathrm{r}, \mathrm{v})\right] / \mathrm{ru}^{1+\mathrm{k}_{1}}
$$

It is readily verified in the case of $(3.20)$ that the equations:

$$
\frac{\partial F_{1}}{\partial u}=0=\frac{\partial F_{1}}{\partial v}
$$

do not give the minimum and that minimum is attained for $u=1 /(1-r)^{2 b}$ and $v=1 /(1+r)^{2 b}$ and this value is given by (2.5). Simple calculation confirms the case of equality for the function $f(z)=f_{4}(z)$ given by (3.18).

In order to maximize $H_{1}(u, v)$ given by $(3.21)$, it is found that the equations:

$$
\frac{\partial \mathrm{H}_{1}}{\partial \mathrm{u}}=0=\frac{\partial \mathrm{H}_{1}}{\partial \mathrm{v}}
$$


give

$$
v=\left[2 r /\left(1-r^{2}\right)^{2} \log (1+r) /(1-r)\right]^{b}
$$

and

$$
\left.\log (1-r)^{2 b} u=\frac{1+b k_{1}}{1+k_{1}}-\frac{1+b k_{1}}{1+k_{1}}+-\frac{2 b r}{1-r}\right] \frac{\left(1-r^{2}\right)}{2 r} \log \left(\frac{1+r}{1-r}\right)
$$

The value of $v$ given by (3.22) lies in the interval (3.19) because,

$$
1>\mathrm{H}(\mathrm{r})>0
$$

but the value of $u$ given by (3.23) lies in the interval (3.19) if

$$
\mathrm{r}-[\mathrm{b}(\mathrm{k}-2)(1+\mathrm{r}) /(\mathrm{b}(\mathrm{k}+2)-4)]<\mathrm{H}(\mathrm{r})+[\mathrm{b}(\mathrm{k}-2)(1-\mathrm{r}) /(\mathrm{b}(\mathrm{k}+2)-4)]
$$

This proves (2.6). The case of equality can be directly confirmed by the function $f(z)$ given by

$$
f_{5}^{\prime}(z)=\frac{(1+z)}{H(r) b\left(1+k_{1}\right)+b k_{1}+r(1-b)} \quad\left(1-z e^{-i t}\right)^{-2 b\left(1+k_{1}\right)}
$$

where

$$
1+r^{2}-2 r \cos t=\left(1-r^{2}\right)^{2} /\left[1+r^{2}-2 r H(r)\right]
$$

when (3.15) does not hold, the maximum value of $\mathrm{H}_{1}(\mathrm{u}, \mathrm{v})$ is attained for

$u=1 /(1+r)^{2 b}, v=1 /(1-r)^{2 b}$ and the corresponding value of $\sup k_{r} v_{k}(1-b)$ is given

by (2.7). Simple calculations confirm the case of equality for the functions given by $(3.15)$.

\section{REFERENCES}

1. NASR, M. A. and AOUF, M. K. Starlike functions of complex order(to appear).

2. NASR, M. A. On a class of function with Rounded Boundary Rotation, Bulletin of the Institute of Mathematics, Academia Sinica 5(1977), 27-36.

3. GoluziN, G. M. Geometric theory of functions of a complex variable, Amer. Math. Soc. Transl. Math. Mono, Providence, R. J., 1969.

4. ZEDERKIEWICEZ, J. Sur la courbure des lignes de niveau dans la classe des functions convexes d'order. Ann. Univ, Mariae Curie-Sklowdowska, A27 (1973), 131-137.

5. EENIGENBURG, $P$. On the radius of curvature of convex analytic functions, Can. J. Math. 23

6. ZMOROVIČ, V. A. On certain variation problems of the theory of Schlict functions. Ukranian Math. J., 4 (1952), 276-298.

7. KEOGH, F. R. Some inequalities for convex and starshaped domains, J. London Math. Soc., 29 (1954), 121-123.

8. NOONAN, J. W. Curvature and radius of curvature for functions with obunded boundary rotation. Can. J. Math. 25(1973), 1015-1023.

9. SINGH, V. Bounds on the curvature of level lines under certain classes of univalent and locally univalent mappings, Indian J. pure app1. Math. 10 (2) (1979), 129-144. 


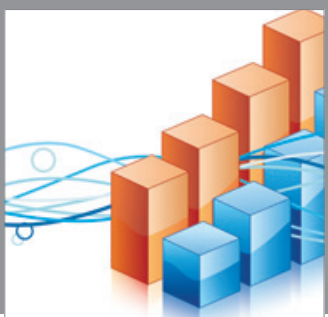

Advances in

Operations Research

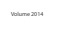

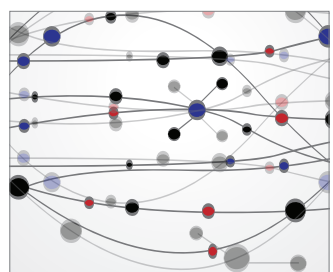

\section{The Scientific} World Journal
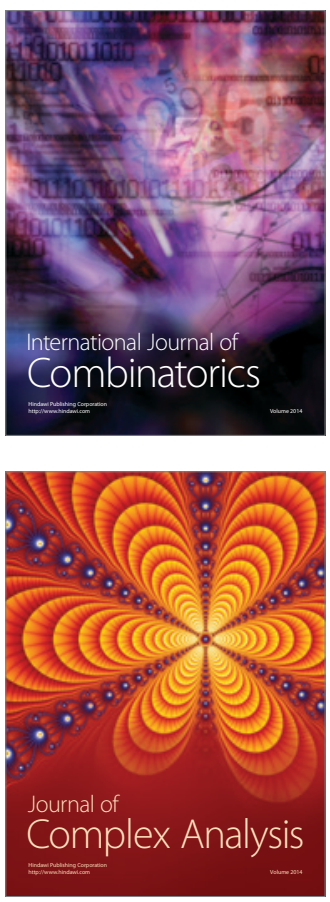

International Journal of

Mathematics and

Mathematical

Sciences
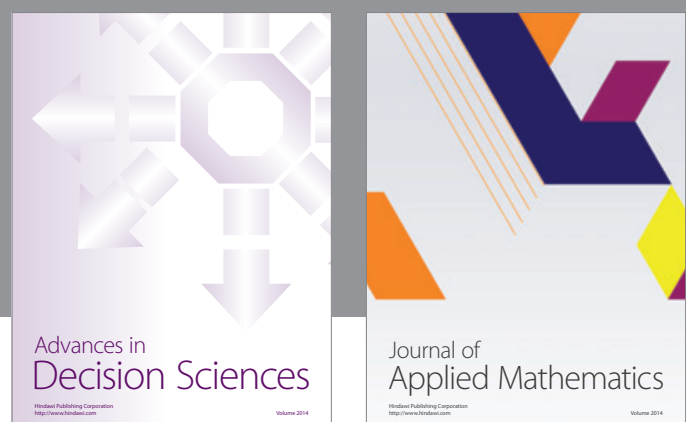

Journal of

Applied Mathematics
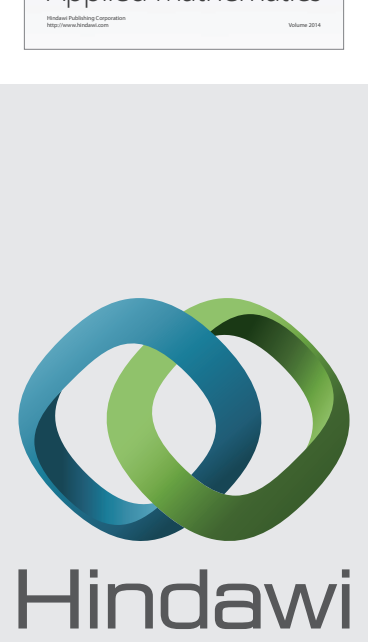

Submit your manuscripts at http://www.hindawi.com
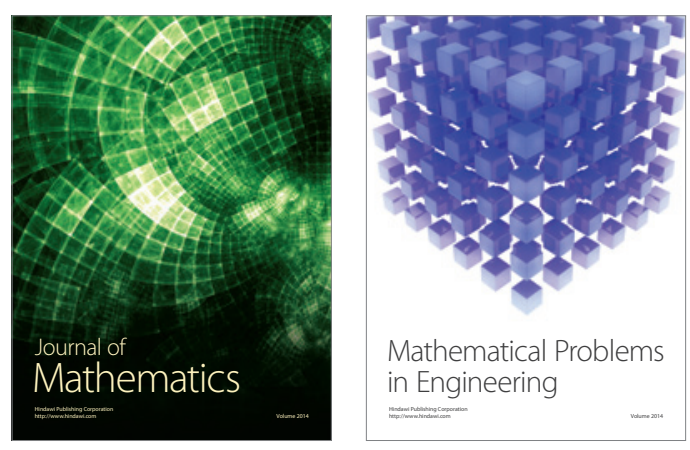

Mathematical Problems in Engineering
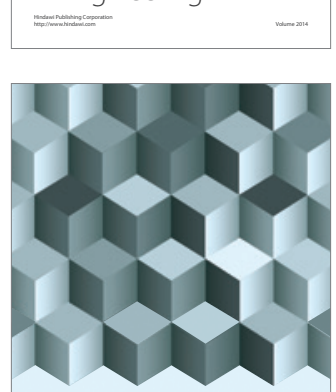

Journal of

Function Spaces
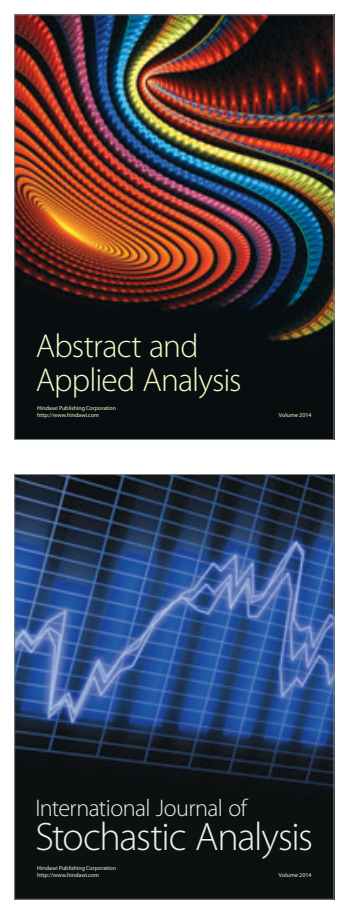

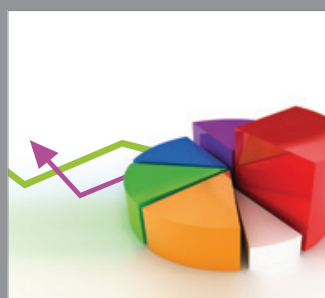

ournal of

Probability and Statistics

Promensencen
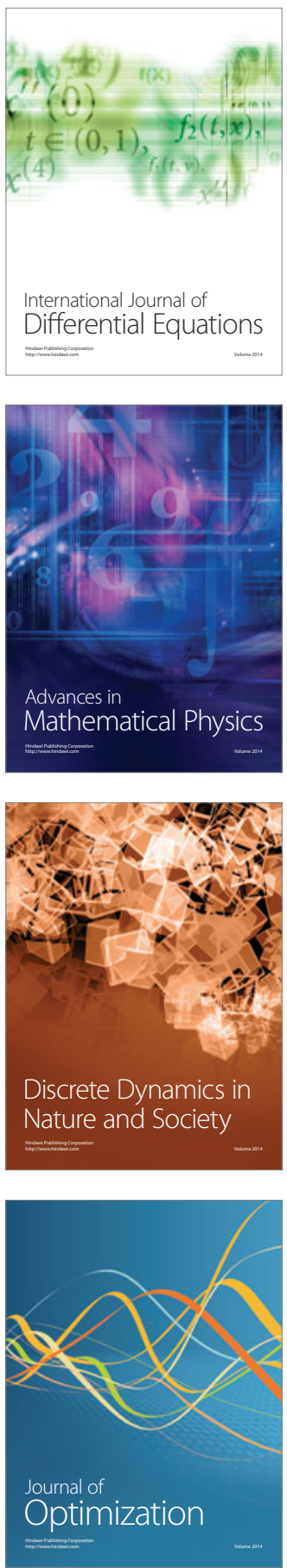